\title{
INSEGURANÇA NA QUALIDADE GENÉTICA DE SEMENTES DE ALFACE PRODUZIDAS NA AMÉRICA DO NORTE E DO SUL
}

\section{UNCERTAINTY IN THE GENETIC QUALITY OF SEED OF LETTUCE PRODUCED IN NORTH AND SOUTH AMERICA}

\author{
Danielle Helena Müller \\ Universidade Federal de Mato Grosso - UFMT \\ Elisangela Clarete Camili \\ Universidade Federal de Mato Grosso - UFMT \\ Mauro Mondin \\ Universidade Federal de Mato Grosso - UFMT \\ Dryelle Sifuentes Pallaoro \\ Universidade Federal de Mato Grosso - UFMT
}

\section{RESUMO}

Objetivou-se comparar a similaridade qualitativa das características fenotípicas de plantas de alface cv. Marisa, desenvolvidas a partir de lotes de sementes produzidas nos Estados Unidos da América (EUA) e no Chile. O delineamento experimental foi em blocos ao acaso, com dois tratamentos (lotes de sementes provenientes dos EUA Lote 1 e Chile - Lote 2) e seis repetições, sendo cada unidade experimental constituída por uma parcela de $3,0 \times 1,2 \mathrm{~m}\left(3,6 \mathrm{~m}^{2}\right)$ e a área útil para avaliação composta de 10 plantas de alface, excluindo-se as primeiras e as últimas plantas de cada linha de cultivo.Avaliou-se nas mudas, 26 dias após a semeadura, o número de folhas; comprimento da maior raiz $(\mathrm{cm})$; massa da matéria seca da parte aérea (MS aérea) e das raízes (MS raízes) (g). No ponto de colheita, antes do corte das plantas, avaliou-se o diâmetro e a altura $(\mathrm{cm})$ e; após a colheita, avaliou-se a massa da matéria fresca total da parte aérea ( $\mathrm{g}$ planta $\left.^{-1}\right)$; a massa da matéria fresca comercial ( $\mathrm{g}$ planta ${ }^{1}$ ); o número de folhas comerciais, contando-se aquelas maiores que $3 \mathrm{~cm}$ de comprimento, iniciando-se pelas folhas basais até a última folha aberta; a massa da matéria fresca do caule (g) e; o comprimento do caule $(\mathrm{cm})$, após a retirada das folhas. Verificou-se diferença nas características agronômicas avaliadas na fase de produção de mudas e no ponto de colheita, destacando-se aquelas provenientes de sementes dos EUA.

Palavras-chave: Lactuca sativa L., Qualidade de sementes, Desempenho agronômico, 


\begin{abstract}
The objective was to compare the qualitative similarity in the phenotypic characteristics of lettuce plants cv. Marisa, developed from seed lots produced in the United States of America (USA) and Chile. The experimental design was randomized block, with two treatments (lots of seeds from USA - lot 1 and Chile - lot 2) and six replications, being each experimental unit constituted by a plot of $3.0 \times 1.2 \mathrm{~m}\left(3.6 \mathrm{~m}^{2}\right)$ and the useful area for evaluation composed of 10 lettuce plants, excluding the first and last plants of each row. Was evaluated in the seedlings, 26 days after sowing, the number of leaves; length of the longer root $(\mathrm{cm})$; dry mass of shoots (DM shoot) and roots (DM roots) (g).At the harvest point, before the cut of the plants, it was evaluated the diameter and height $(\mathrm{cm})$ and; after harvest, it was evaluated the total fresh mass of the shoot $(\mathrm{g}$ planta $\left.{ }^{-1}\right)$, the commercial fresh mass $\left(g_{\text {planta }}^{-1}\right.$ ); the number of commercial leaves, counting those were bigger than $3 \mathrm{~cm}$ of length, beginning at the basal until the last open leave; the fresh mass of the stem $(\mathrm{g})$ and; the stem length $(\mathrm{cm})$, after removal the leaves. It were verified differences in agronomic characteristics evaluated in the seedling production phase and in the harvest point, especially those from US seeds.
\end{abstract}

Keywords: Lactuca sativa L., Seeds quality, Agronomic performance, Commercial production

\title{
INTRODUÇÃO
}

Competir com vantagem no mercado de hortaliças, não é somente ter habilidade na gestão da propriedade agrícola; se faz necessário também, uma eficiente retaguarda científica e tecnológica que garanta elevado padrão de qualidade das cultivares e de suas sementes.

Atualmente o mercado especializou-se e o consumidor tornou-se mais exigente; portanto, a tipologia do produto é decisiva para se ter alto valor comercial. Nos campos de produção de hortaliças, sanidade e tolerância às condições ambientais adversas, combinadas com alta produtividade e frequência de oferta do produto, passaram a ser vitais para o retorno do investimento e permanência na atividade.

O desempenho agronômico de cultivares de hortaliças depende da carga genética e da interação entre os vários fatores de produção como temperatura, umidade, solo, adubação, presença de pragas e doenças, entre outros. Isto significa que, sob determinadas situações, o comportamento ou as características das plantas podem sofrer variações. 
Por este motivo, objetivou-se comparar a similaridade qualitativa das características fenotípicas de plantas de alface, desenvolvidas a partir de dois lotes de sementes produzidas em países diferentes.

\section{MATERIAL E MÉTODOS}

Os testes para avaliação do desenvolvimento e da produção de plantas de alface foram conduzidos em área de produtor, localizada no assentamento Santo Antonio da Fartura, município de Campo Verde-MT, situado a uma altitude média de 749 metros, latitude $15^{\circ} 32^{\prime} 44^{\prime \prime}$ S e longitude $55^{\circ} 9^{\prime} 59 " \mathrm{~W}$, no período de março a junho de 2012.

O solo que ocorre na região é classificado predominantemente como Latossolo Vermelho Distrófico, de textura franco-areno-argilosa. O clima, segundo o sistema de classificação de Köppen, é denominado Aw, caracterizado por apresentar inverno seco de maio a setembro e, verão chuvoso de outubro a março; com precipitação média anual de $2007 \mathrm{~mm}$ e temperatura média de $26^{\circ} \mathrm{C}$ (Fernandes \& Scaramuzza, 2007).

O delineamento experimental adotado foi o de blocos ao acaso, com dois tratamentos (lotes de sementes provenientes dos Estados Unidos - Lote 1 e Chile - Lote 2) e seis repetições, sendo cada unidade experimental constituída por uma parcela de 3,0 × 1,2 m, perfazendo 3,6 m², e área útil para avaliação composta de 10 (dez) plantas de alface, excluindo-se as primeiras e as últimas plantas de cada linha de cultivo. Nos canteiros o espaçamento utilizado foi de $0,25 \times 0,25 \mathrm{~m}$, com cinco fileiras por canteiro. Os tratos culturais seguiram o convencionalmente adotado pelo produtor.

Realizou-se a semeadura da alface do tipo crespa cv. Marisa, em bandejas de polietileno preto com capacidade para 288 células, utilizando como substrato produto comercial a base de vermiculita e matéria orgânica (Tropstrato HT Hortaliças). As mudas foram avaliadas no dia do transplantio para os canteiros definitivos, quando apresentavam em média quatro folhas definitivas, aos 26 dias após a semeadura, mensurando-se as seguintes características: número de folhas; comprimento da maior raiz $(\mathrm{cm})$, com uso de régua; massa da matéria seca da parte aérea (MS aérea) e das raízes (MS

Revista Internacional de Ciências · v.5 - n.2 · jul./dez. 2015 
raízes), em gramas, determinadas pelo acondicionamento separado em sacos de papel, mantidos em estufa a $80^{\circ} \mathrm{C}$ por $24 \mathrm{~h}$. Para tanto, foram avaliadas 20 mudas provenientes de cada lote de sementes.

A colheita da alface foi realizada quando as plantas apresentavam padrão comercial, com máximo desenvolvimento vegetativo, mas ainda com folhas tenras e sem indícios de pendoamento precoce (florescimento), aos 36 dias após o transplantio. No momento da colheita foram avaliadas 10 plantas de cada tratamento (lote de sementes), escolhidas aleatoriamente entre as plantas consideradas úteis, sendo cinco da parte interna do canteiro e cinco das fileiras laterais, parte externa do canteiro. Ainda no campo, as plantas foram avaliadas quanto ao diâmetro e a altura média. Depois da colheita, as plantas foram avaliadas quanto a: massa da matéria fresca total da parte aérea (g planta-1), obtida pela pesagem das plantas cortadas rente ao solo, em balança analítica, com precisão de $5 \mathrm{~g}$ e; massa da matéria fresca comercial ( $\mathrm{g}$ planta $^{-1}$ ), após eliminação das folhas externas, danificadas ou sujas, sem valor comercial. $\mathrm{Na}$ sequência efetuou-se a avaliação do número de folhas comerciais, contando-se aquelas maiores que $3 \mathrm{~cm}$ de comprimento, iniciandose pelas folhas basais até a última folha aberta (Oliveira et al., 2002). Em relação ao caule ("coração"), a massa da matéria fresca foi obtida em gramas e, o comprimento foi através de medida tomada longitudinalmente, com o uso de régua graduada em $\mathrm{cm}$ (adaptado de Yuri et al., 2004), após a retirada das folhas.

Os dados foram submetidos à análise de variância pelo teste $F$, e as médias comparadas pelo teste de Tukey a $5 \%$ de probabilidade, utilizando-se 0 sistema Sisvar (Ferreira, 2008).

\section{RESULTADOS E DISCUSSÃO}

Verifica-se diferença entre os lotes oriundos dos EUA e Chile, desde a fase de produção das mudas, destacando-se aquelas provenientes de sementes dos EUA (Tabela 1). Tais resultados podem ser atribuídos à qualidade inicial das sementes, visto que lotes diferentes foram utilizados para avaliação.

Revista Internacional de Ciências · v.5 - n.2 · jul./dez. 2015 
Tabela 1. Número de folhas, comprimento da maior raiz $(\mathrm{cm})$, massa da matéria seca da parte aérea e das raízes (g) de mudas de alface (Lactuca sativa L.) de dois lotes do cultivar Marisa. Campo Verde/MT, 2012.

\begin{tabular}{|c|c|c|c|c|}
\hline Lotes & $\begin{array}{l}\text { Número } \\
\text { de folhas }\end{array}$ & $\begin{array}{l}\text { Comprimento } \\
\text { raiz }\end{array}$ & MS aérea & MS raízes \\
\hline 1 - EUA & $4,45^{x} a$ & $6,23 \mathrm{a}$ & $0,051 \mathrm{a}$ & $0,021 \mathrm{a}$ \\
\hline 2- Chile & $3,95 \mathrm{~b}$ & $6,40 \mathrm{a}$ & $0,043 \mathrm{~b}$ & $0,015 \mathrm{~b}$ \\
\hline CV (\%) & 13,93 & 14,79 & 23,94 & 29,77 \\
\hline
\end{tabular}

x Médias de vinte repetições seguidas pela mesma letra na coluna não diferem entre si pelo teste de Tukey $(p<0,05)$.

Dos parâmetros avaliados nas mudas, apenas o comprimento da maior raiz não diferiu estatisticamente entre os lotes. O número de folhas foi maior para o lote dos EUA, com valor de 4,45 folhas por planta, em comparação as 3,95 folhas das mudas produzidas a partir de sementes chilenas. Lédo et al. (1996) observaram que mudas de alface produzidas em bandejas de poliestireno expandido ("isopor") com 288 células, usando como substrato produto comercial, aos 22 dias, apresentaram de quatro a seis folhas definitivas; número similar ao obtido nas mudas do lote dos EUA, que atingiram quantidade suficiente de folhas para serem transplantadas aos 26 dias (Silva \& Queiroz, 2014).

No parâmetro massa da matéria seca da parte aérea e das raízes, observou-se que as mudas que atingiram maior valor corresponderam ao Lote 1 (EUA). Isto indica que as mudas obtidas das sementes do lote dos EUA absorveram normalmente os nutrientes $e$ estes foram assimilados $e$ convertidos em massa seca, com maior eficiência em comparação às que foram obtidas do lote chileno. Segundo Nakagawa (1999) o teste de massa da matéria seca de plântulas realizado em campo pode ser utilizado como um indicativo para determinação do vigor de lotes de sementes.

Seguindo a mesma tendência, as plantas do lote de sementes norteamericano apresentaram valores superiores para as características avaliadas no ponto de colheita (Tabelas 2 a 5). Considerando o diâmetro (Tabela 2), a massa da matéria fresca (Tabela 3) e o número de folhas por planta (Tabela 4) como os caracteres agronômicos mais importantes para a comercialização, verificou-se melhor desempenho para o lote proveniente dos EUA, com valores variando entre 31,93 a 33,25 cm de diâmetro, de 187,17 a 198,03g de massa 
da matéria fresca comercial, e de 23,07 a 23,30 folhas, em plantas colhidas interna e externamente aos canteiros.

Tabela 2. Diâmetro $(\mathrm{cm})$ e altura $(\mathrm{cm})$ de plantas de alface (Lactuca sativa L.) de dois lotes do cultivar Marisa, colhidas interna (In) e externamente (Ex) aos canteiros. Campo Verde/MT, 2012.

\begin{tabular}{|c|c|c|c|c|}
\hline Lotes & $\begin{array}{c}\text { Diâmetro } \\
\text { In }\end{array}$ & $\begin{array}{c}\text { Diâmetro } \\
\text { Ex }\end{array}$ & $\begin{array}{c}\text { Altura } \\
\text { In }\end{array}$ & $\begin{array}{c}\text { Altura } \\
\text { Ex }\end{array}$ \\
\hline EUA & $31,93^{x} a$ & $33,25 \mathrm{a}$ & $30,28 \mathrm{a}$ & $25,47 a$ \\
\hline Chile & $29,97 \mathrm{~b}$ & $30,52 \mathrm{~b}$ & $24,87 \mathrm{~b}$ & $21,08 \mathrm{~b}$ \\
\hline CV (\%) & 1,85 & 2,72 & 6,27 & 4,74 \\
\hline
\end{tabular}

x Médias de seis repetições seguidas pela mesma letra na coluna não diferem entre si pelo teste de Tukey $(p<0,05)$.

Tabela 3. Massa da matéria fresca total (MMFT) e comercial (MMFC), em gramas, de plantas de alface (Lactuca sativa L.) de dois lotes do cultivar Marisa, colhidas interna (In) e externamente (Ex) aos canteiros. Campo Verde/MT, 2012.

\begin{tabular}{|c|c|c|c|c|}
\hline Lotes & $\begin{array}{c}\text { MMFT } \\
\text { In }\end{array}$ & $\begin{array}{c}\text { MMFT } \\
\text { Ex }\end{array}$ & $\begin{array}{c}\text { MMFC } \\
\text { In }\end{array}$ & $\begin{array}{c}\text { MMFC } \\
\text { Ex }\end{array}$ \\
\hline EUA & $223,50^{x} a$ & $212,80 a$ & $198,03 \mathrm{a}$ & $187,17 \mathrm{a}$ \\
\hline Chile & $206,53 \mathrm{a}$ & $190,40 \mathrm{a}$ & 175,27 b & $162,87 \mathrm{~b}$ \\
\hline CV (\%) & 6,22 & 8,31 & 6,73 & 8,94 \\
\hline
\end{tabular}

x Médias de seis repetições seguidas pela mesma letra na coluna não diferem entre si pelo teste de Tukey $(p<0,05)$.

Tabela 4. Número e massa da matéria fresca de folhas comerciais (MMFF), em gramas, de plantas de alface (Lactuca sativa L.) de dois lotes do cultivar Marisa, colhidas interna (In) e externamente (Ex) aos canteiros. Campo Verde/MT, 2012.

\begin{tabular}{|c|c|c|c|c|}
\hline Lotes & $\begin{array}{c}\text { Folhas } \\
\text { In }\end{array}$ & $\begin{array}{c}\text { Folhas } \\
\text { Ex }\end{array}$ & $\begin{array}{c}\text { MMFF } \\
\text { In }\end{array}$ & $\begin{array}{c}\text { MMFF } \\
\text { Ex }\end{array}$ \\
\hline EUA & $23,30^{x} a$ & $23,07 \mathrm{a}$ & $173,23 \mathrm{a}$ & $166,87 \mathrm{a}$ \\
\hline Chile & $20,90 \mathrm{~b}$ & $19,83 \mathrm{~b}$ & $154,73 \mathrm{~b}$ & $147,20 \mathrm{~b}$ \\
\hline CV (\%) & 4,07 & 3,96 & 6,26 & 8,11 \\
\hline
\end{tabular}

* Médias de seis repetições seguidas pela mesma letra na coluna não diferem entre si pelo teste de Tukey $(p<0,05)$.

As plantas do lote dos EUA apresentaram maior porte, com $30,28 \mathrm{~cm}$ de altura para aquelas colhidas internamente aos canteiros, e $25,47 \mathrm{~cm}$ em plantas que foram colhidas nas linhas externas dos canteiros. A altura das plantas está diretamente relacionada ao maior desempenho no acúmulo de massa da matéria fresca. Segundo Lédo et al. (2000) produtores comercializam plantas mais longas para obter maior peso total. Contudo o processo de alongamento, que antecede a floração, pode desclassificar o produto para 0 mercado caso ocorra elevação na produção do látex neste período. 
A massa da matéria fresca comercial foi maior para as plantas produzidas com sementes oriundas dos EUA, sendo este um fator de qualidade a ser considerado, permitindo que as plantas atinjam maiores preços de comercialização, haja vista que esta é feita geralmente por unidade ("pé ou cabeça"). Esses resultados corroboram com os observados por Kissmann et al. (2010), em que maior massa da matéria fresca foi obtida em plântulas de Stryphnodendron polyphyllum oriundas de sementes de lote com qualidade fisiológica superior.

Além disso, verifica-se que a massa da matéria fresca comercial da alface, associada ao seu valor de comercialização, estão entre os principais parâmetros que influem na escolha desta hortaliça pelo consumidor, assim sendo, as cultivares que apresentam maior massa fresca são as preferidas para consumo (Schumacher et al., 2012).

Não houve diferenças entre o desempenho dos lotes no crescimento do caule das plantas, assim o alongamento do caule manteve-se dentro do padrão esperado para a cultivar Marisa (Tabela 5).

Tabela 5. Comprimento $(\mathrm{cm})$ e massa da matéria fresca do caule (MMFC), em gramas, de plantas de alface (Lactuca sativa L.) de dois lotes do cultivar Marisa, colhidas interna (In) e externamente (Ex) aos canteiros. Campo Verde/MT, 2012.

\begin{tabular}{lllll}
\hline Lotes & Comprimento & Comprimento & MMFC M
\end{tabular}

\begin{tabular}{|c|c|c|c|c|}
\hline & In & Ex & In & Ex \\
\hline EUA & $7,02^{x} a$ & $5,33 \mathrm{a}$ & $24,80 \mathrm{a}$ & $20,30 a$ \\
\hline Chile & $7,20 \mathrm{a}$ & $4,98 \mathrm{a}$ & $20,53 \mathrm{a}$ & $15,67 \mathrm{~b}$ \\
\hline CV (\%) & 16,51 & 11,05 & 15,15 & 17,28 \\
\hline
\end{tabular}

× Médias de seis repetições seguidas pela mesma letra na coluna não diferem entre si pelo teste de Tukey $(p<0,05)$.

O maior comprimento e massa do caule, mesmo sem diferença estatística, podem estar relacionados com o maior número de folhas em plantas produzidas a partir de sementes provenientes dos EUA, pois, precisam de maior espaço para se arranjar na planta. Segundo Yuri et al. (2004) na prática, caules de até $6,0 \mathrm{~cm}$ seriam os mais adequados, sendo aceitáveis aqueles com até $9,0 \mathrm{~cm}$ de comprimento, e inaceitáveis ou menos recomendados para comercialização valores acima disso.

A avaliação do potencial de cultivares provenientes de diferentes regiões agroclimáticas, além de proporcionar sustentabilidade a pesquisas 
subsequentes, é imprescindível para o aumento da rentabilidade das culturas, e isso está diretamente relacionado ao uso de cultivares mais adaptadas em termos de tolerância ao pendoamento e outras características agronômicas relevantes.

A variação de desempenho de diferentes genótipos de alface tem sido observada nas diversas regiões do Brasil, onde cada cultivar expressa de forma distinta seu potencial genético quando submetidas em diferentes condições ambientais (Queiroz et al., 2014).

Deste modo, a avaliação dos lotes de sementes de alface é uma ferramenta importante para verificar a condição de vigor e crescimento das plantas, uma vez que diferentes materiais podem responder de maneira diferencial, alcançando melhores índices de produtividade em um ensaio comparativo. Nesse contexto, verificou-se o comportamento produtivo superior de plantas provenientes de sementes do lote dos EUA nas condições de cultivo comercial em Campo Verde-MT.

\section{CONCLUSÃO}

Há diferenciação da qualidade de lotes de sementes de alface, verificada pelo desempenho agronômico das plantas, o que determina diretamente a qualidade superior do produto final do lote de sementes proveniente dos EUA.

\section{REFERÊNCIAS BIBLIOGRÁFICAS}

FERNANDES, F.C.S., SCARAMUZZA, W.L.M.P. Produção e decomposição da liteira em fragmento florestal em Campo Verde (MT). Revista de Ciências Agrárias, v.47, p.173-186, $2007 . \quad$ Disponível em:<https://periodicos.ufra.edu.br/index.php?journal=ajaes\&page=article\&op=vi ew\&path\%5B\%5D=200\&path\%5B\%5D=93>. Acesso em 17 jun de 2014.

FERREIRA, D.F. SISVAR: um programa para análises e ensino de estatística. Revista Symposium, v.6, p.36-41, 2008.

KISSMANN, C., SCALON, S.P.Q., MOTA, L.H.S., VIEIRA, M.C. Germinação de sementes de Stryphnodendron Mart., osmocondicionadas. Revista Brasileira de Sementes, v.32, p.26-35, 2010. Disponível em: < 
http://www.scielo.br/scielo.php?pid=S0101-

31222010000200003\&script=sci_arttext>. Acesso em 20 de jul de 2012.

LÉDO, F.J.S., SOUZA, J.Á., SIVIERO, A., ARAÚJO, H.M., SILVA, M.R. Introdução e avaliação de cultivares de alface (Lactuca sativa L.) para 0 período seco no Acre. Rio Branco: EMBRAPA/Centro de Pesquisa Agroflorestal do Acre. 4p., 1996. (Pesquisa em Andamento, 87).

LÉDO, F.J.S., SOUZA, J.Á., SILVA, M.R. Desempenho de cultivares de alface no Estado do Acre. Horticultura Brasileira, v.18, p.225-228, 2000. Disponível em: < http://www.scielo.br/pdf/hb/v18n3/v18n3a17>. Acesso em 13 jul de 2012.

NAKAGAWA, J. Testes de vigor baseados no desempenho das plântulas. In: KRZYZANOSKI, F.C., VIEIRA, R.D., FRANÇA NETO, J.B. (Ed.). Vigor de sementes: conceitos e testes. Londrina: ABRATES, 24p. 1999.

OLIVEIRA, A.M., BEZERRA NETO, F., NEGREIROS, M.Z., OLIVEIRA, E.Q., GONDIM, A.R.O., PORTO, D.R.Q., FREITAS, K.K.C. Desempenho de cultivares de alface americana em consorciação com cenoura em dois sistemas de cultivo em faixas. Revista Caatinga, v.15, p.73-79, 2002. Disponível em:< http://www.abhorticultura.com.br/biblioteca/arquivos/download/biblioteca/olfg40 69c.pdf>. Acesso em 10 jun de 2014.

QUEIROZ, J.P.S., COSTA, A.J.M., NEVES, L.G., SEABRA JUNIOR, S., BARELLI, M.A.A. Estabilidade fenotípica de alfaces em diferentes épocas e ambientes de cultivo. Revista Ciência Agronômica, v.45, p.276-283, 2014. Disponível em:< http://www.ccarevista.ufc.br/seer/index.php/ccarevista/article/view/1913/938>. Acesso em 23 jan de 2015.

SILVA, E.C., QUEIROZ, R.L. Formação de mudas de alface em bandejas preenchidas com diferentes substratos. Bioscience Journal, v.30, p.725-729, 2014. Disponível em:< http://www.seer.ufu.br/index.php/biosciencejournal/article/view/18099/13932>. Acesso em 13 março de 2015.

SCHUMACHER, P.V., MOTA, J.H., YURI, J.E., RESENDE, G.M. Competição de cultivares de alface em Jataí-GO. Horticultura Brasileira, v.30, p.27272731, $2012 . \quad$ Disponível em:< http://ainfo.cnptia.embrapa.br/digital/bitstream/item/67721/1/Jony-EishiYuri5.pdf>. Acesso em jun de 2013.

YURI, J.E., MOTA, J.H., RESENDE, G.M., SOUZA, R.J., RODRIGUES JUNIOR, J.C. Desempenho de cultivares de alface tipo americana em cultivo 
de outono no sul de Minas Gerais. Ciência e Agrotecnologia, v.28, p.284-288, 2004. Disponível em:< http://www.scielo.br/scielo.php?pid=S141370542004000200005\&script=sci_abstract\&tlng=pt>. Acesso em jul de 2012.

Recebido:06/10/2015 Aprovado:04/12/2015 